\title{
Thoracolaparoscopic carinal resection and reconstruction using pedicle omental flap
}

\author{
Takeo Nakada, Takashi Ohtsuka \\ Division of Thoracic Surgery, Department of Surgery, The Jikei University School of Medicine, Tokyo, Japan \\ Correspondence to: Takeo Nakada. Division of Thoracic Surgery, Department of Surgery, The Jikei University School of Medicine, Nishishinbashi \\ 3-19-18, Minatoku, Tokyo 105-8471, Japan. Email: takeo521@hotmail.co.jp. \\ Comment on: Chen J, Ang KL, Wang C, et al. Minimally invasive carinal reconstruction using bronchial flap and omental flap reinforcement. Ann \\ Thorac Surg 2021. [Epub ahead of print]. doi: 10.1016/j.athoracsur.2021.06.014.
}

Submitted Aug 20, 2021. Accepted for publication Sep 07, 2021.

doi: $10.21037 /$ tlcr-21-662

View this article at: https://dx.doi.org/10.21037/tlcr-21-662

Video-assisted thoracoscopic surgery (VATS) for pulmonary resection has advantages in terms of postoperative pain management, chest tube drainage period, postoperative hospitalization, pulmonary function, and activity recovery (1). VATS has been indicated for pulmonary resections worldwide. However, VATS has rarely been performed in carinal reconstruction since it is technically demanding. Considering the complexity of surgical techniques, medical teams should carefully plan each surgical procedure and perioperative management.

In this study, Chen et al. successfully performed a thoracolaparoscopic carinal resection and reconstruction using a pedicle omental flap (2). The histological type and location of the tumor are essential considerations when planning a surgery. The adenoid cystic carcinoma in the case was limited to the carinal aspect of both bronchi. The distal left main bronchus, right upper lobe bronchus, and bronchus intermedius, were not involved. The authors used the bronchial flap technique as a reference. However, surgical and radiographic schemas for pedicle bronchial flap reconstructions have not been established. Therefore, the surgical procedure was converted into a right main bronchus resection with partial carinal resection $(\mathrm{RBR}+\mathrm{PCR})$ and carinal reconstruction.

Excessive anastomotic tension is the most critical cause of circumferential tracheal or carinal resection failure. It is ideal to reconstruct large tracheal defects to maintain a wellvascularized, non-collapsible, and less tense anastomosis site. Bronchial flap reconstruction is advantageous in cases of central massive defects due to the previous ideal condition without bronchial circumferential resections or major mobilization (3). Peng et al. evaluated 73 patients, who underwent non-circumferential tracheal or carinal resection (4). A total of six types of bronchial flap reconstructions were presented. According to these surgical indications, right pneumonectomy and left bronchial defect repair with a flap were the ideal management for the present case. Chen et al. successfully performed a carinal reconstruction, preserving the right lung, without using the bronchial flap technique.

In 1982, Grillo published a report on carinal resection and reconstruction (5). Carinal reconstruction is a challenging procedure that requires complex surgical techniques. Additionally, RBR+PCR has rarely been performed. Li et al. performed three cases of multiportal VATS RBR+PCR, including two patients who underwent the bronchus intermedius procedure (6). However, the vital surgical factors for VATS RBR+PCR remain unknown. In VATS bronchial anastomosis, controlling the needle angle and thread through the port is technically demanding. The complete continuous suturing technique was reportedly beneficial in bronchial anastomosis. There were no significant differences between continuous and interrupted sutures for bronchial anastomosis in terms of anastomoticrelated complications, such as bronchopleural fistula (BPF), dehiscence of the suture line, and late stenosis (7). Li et al. suggested that a running suture was a viable retention suture, that provided a better view. The anastomosis took 40-50 minutes in their report. Tension-free anastomosis requires mobilizing the proximal and distal airways. Additionally, it is crucial to match the anastomosis orifices 
between the bronchus and trachea or carina. A mismatch between the orifices on the tracheal or carinal side, and the bronchial side warrants adjusting the tracheal side orifice via suturing. Thus, the tracheal orifice is enlarged to create matching orifices. Chen placed a 4-5-cm main port, which was reportedly large for VATS. I am very impressed if the authors relied only their monitors for their vision, without using the direct vision through the main port, to overcome these obstacles. Experienced surgical and anesthetic teams can perform challenging carinal resections and reconstructions. According to Gonzalez-Rivas et al., surgeons, that have performed at least 200 VATS lobectomies and 20 cases of open sleeve procedures, are considered experienced in thoracoscopic sleeve resection (7).

Tracheal or carinal resection using the thoracoscopic approach requires total airway management, in cooperation with an anesthesiologist. In partial carinal reconstruction, a single-lumen endotracheal tube is preferred over a double-lumen tube because it provides more space for reconstruction (6). In other tracheal and carinal surgeries, cross-field ventilation is indicated. In VATS, a cross-field endobronchial tube is placed on an additional port when necessary. High-frequency jet ventilation is an effective strategy for intraoperative ventilation. It can be inserted through the endotracheal tube for better ventilation due to the small diameter of the catheter. This achieves a clear visual field without interfering with the lateral cartilaginous or membranous portion of the anastomosis (1). Further, intraoperative airway management requires preparation according to the progress of surgery, including emergencies. Surgeons and anesthesiologists should consider preparing peripheral femoral veno-arterial extracorporeal membrane oxygenation machines in cases of unexpected emergencies.

$\mathrm{BPF}$ is a life-threatening complication, occurring in 3.7\% to $16.7 \%$ of patients undergoing sleeve resection $(8,9)$. To prevent BPF, tissue flaps are used to cover the anastomosis. The disadvantages of pleural flaps include their thinness and inadequate blood supply (10). The sizes of intercostal muscle flaps are insufficient to cover airway defects (11). Extrathoracic muscle flaps, particularly the latissimus dorsi, serratus anterior, and pectoralis major, are useful for trachea-carinal airway reconstruction. The omentum is particularly effective in buttressing the closure of the BPF. Puskas et al. evaluated 42 patients with postoperative bronchial fistulas. Omental buttressing was successful in 23 of 25 patients (92\%), while muscle buttressing was successful in nine of 14 patients (64\%). The BPFs buttressed with the pleura were unsuccessful (0/2) (12). Additionally,
Duan studied 50 patients with chronic persistent empyema, treated with a pedicled omentum flap transplant, including 32 patients with BPF (13). Operative interventions were successful in $93.1 \%$ of patients, and the BPF closure rate was $89.5 \%$. Thoracic flaps are the preferred choice for buttressing bronchial anastomosis because they avoid the abdominal opening for harvesting the omentum flap. The laparoscopically harvested pedicled omental flap (LHPOF) is less invasive for the chest and abdominal wall. LHPOF has been performed for nearly 20 years. In particular, this technique was frequently used in breast reconstruction (14). The LHPOF provides inconspicuous skin incisions, and hastens the recovery of bowel function and postoperative pain. The LHOPOF has been reported in thoracic surgery. Acarturk reported nine patients who underwent LHPOF for chest wall and intrathoracic reconstruction (15). The omentum can be safely used as a versatile flap in thoracic surgery for various purposes. Using LPHO effectively enhanced the bronchial anastomosis without compromising the benefits of VATS since it lessens the damage to the chest wall. Surgeons should establish the indications for LPHO based on the following points. In patients with a poor nutrition status, the volume of the omentum is insufficient. The amount of fat in the omentum should be assessed via preoperative abdominal computed tomography. There is currently no consensus on where the omentum passes through the diaphragm. However, diaphragmatic hernias or twisting, and necrosis of the omentum should be evaluated. Another concern is the misalignment of the reinforcement in relation to diaphragmatic movement.

VATS carinal resection requires complex surgical techniques and prudent intraoperative airway management. The authors successfully performed a safe and radical carinal resection using the thoracolaparoscopic approach. They must be congratulated for their excellent surgical results. However, there are still unanswered questions, related to the surgical indications and outcomes. Therefore, further case reports are needed.

\section{Acknowledgments}

The authors would like to thank Editage (https://www. editage.jp) for English language review.

Funding: None.

\section{Footnote}

Provenance and Peer Review: This article was commissioned 
by the editorial office, Translational Lung Cancer Research. The article did not undergo external peer review.

Conflicts of Interest: Both authors have completed the ICMJE uniform disclosure form (available at https://dx.doi. org/10.21037/tlcr-21-662). The authors have no conflicts of interest to declare.

Ethical Statement: The authors are accountable for all aspects of the work in ensuring that questions related to the accuracy or integrity of any part of the work are appropriately investigated and resolved.

Open Access Statement: This is an Open Access article distributed in accordance with the Creative Commons Attribution-NonCommercial-NoDerivs 4.0 International License (CC BY-NC-ND 4.0), which permits the noncommercial replication and distribution of the article with the strict proviso that no changes or edits are made and the original work is properly cited (including links to both the formal publication through the relevant DOI and the license). See: https://creativecommons.org/licenses/by-nc-nd/4.0/.

\section{References}

1. Gonzalez-Rivas D, Yang Y, Stupnik T, et al. Uniportal video-assisted thoracoscopic bronchovascular, tracheal and carinal sleeve resections †. Eur J Cardiothorac Surg. 2016 Jan;49 Suppl 1:i6-16.

2. Chen J, Ang KL, Wang C, et al. Minimally invasive carinal reconstruction using bronchial flap and omental flap reinforcement. Ann Thorac Surg 2021. [Epub ahead of print]. doi: 10.1016/j.athoracsur.2021.06.014.

3. Chen QK, Jiang GN, Ding JA, et al. Reconstruction of the lower trachea using a pedicled autologous bronchial flap. Ann Thorac Surg 2010;89:e29-30.

4. Peng Q, Zhang L, Ren Y, et al. Reconstruction of Long Noncircumferential Tracheal or Carinal Resections With Bronchial Flaps. Ann Thorac Surg 2019;108:417-23.

5. Grillo HC. Carinal reconstruction. Ann Thorac Surg 1982;34:356-73.

Cite this article as: Nakada T, Ohtsuka T. Thoracolaparoscopic carinal resection and reconstruction using pedicle omental flap. Transl Lung Cancer Res 2021;10(9):3855-3857. doi: 10.21037/ tlcr-21-662
6. Li J, Wang W, Jiang L, et al. Video-Assisted Thoracic Surgery Resection and Reconstruction of Carina and Trachea for Malignant or Benign Disease in 12 Patients: Three Centers' Experience in China. Ann Thorac Surg 2016;102:295-303.

7. Gonzalez-Rivas D, Soultanis KM, Garcia A, et al. Uniportal video-assisted thoracoscopic lung sparing tracheo-bronchial and carinal sleeve resections. J Thorac Dis 2020;12:6198-209.

8. Mitchell JD, Mathisen DJ, Wright CD, et al. Resection for bronchogenic carcinoma involving the carina: long-term results and effect of nodal status on outcome. J Thorac Cardiovasc Surg 2001;121:465-71.

9. Yildizeli B, Fadel E, Mussot S, et al. Morbidity, mortality, and long-term survival after sleeve lobectomy for non-small cell lung cancer. Eur J Cardiothorac Surg 2007;31:95-102.

10. Anderson TM, Miller JI Jr. Use of pleura, azygos vein, pericardium, and muscle flaps in tracheobronchial surgery. Ann Thorac Surg 1995;60:729-33.

11. Ris HB, Krueger T, Cheng C, et al. Tracheo-carinal reconstructions using extrathoracic muscle flaps. Eur J Cardiothorac Surg 2008;33:276-83.

12. Puskas JD, Mathisen DJ, Grillo HC, et al. Treatment strategies for bronchopleural fistula. J Thorac Cardiovasc Surg 1995;109:989-95; discussion 995-6.

13. Duan M, Chen G, Wang T, et al. One-stage pedicled omentum majus transplantation into thoracic cavity for treatment of chronic persistent empyema with or without bronchopleural fistula. Eur J Cardiothorac Surg 1999;16:636-8.

14. Wang $\mathrm{ZH}, \mathrm{Xin} \mathrm{P}, \mathrm{Qu} \mathrm{X}$, et al. Breast reconstruction using a laparoscopically harvested pedicled omental flap after endoscopic mastectomy for patients with breast cancer: an observational study of a minimally invasive method. Gland Surg 2020;9:676-88.

15. Yildizeli B, Fadel E, Mussot S, et al. Morbidity, mortality, and long-term survival after sleeve lobectomy for non-small cell lung cancer. Eur J Cardiothorac Surg 2007;31:95-102. 